\title{
A MAÇONARIA BRASILEIRA E A DEFESA DO ENSINO LAICO (SÉCULO XIX)
}

Eliane Lucia Colussi ${ }^{1}$

Resumo: O presente artigo objetiva analisar a influência da maçonaria na defesa do ensino laico durante o período imperial brasileiro. A maçonaria, presente na história brasileira desde o período anterior a proclamação da independência, assumiu durante o século XIX, posicionamentos abertamente anticlericais. O campo da educação foi considerado, pelos maçons, fundamental na sua luta anticlerical.

Unitermos: história política, maçonaria, educação, Igreja Católica.

Na segunda metade do século XIX, a maçonaria foi a principal porta-voz dos setores sociais defensores de posicionamentos anticlericais. $\mathrm{O}$ anticlericalismo maçônico era compatível com a defesa genérica do ideário liberal e cientificista da maior parte da ilustração brasileira no período. Inimigos desde meados do século XVIII, maçonaria e Igreja Católica protagonizaram um embate que cresceu ainda mais no século XIX.

Os maçons utilizaram-se da imprensa, da política parlamentar, das associações e clubes literários ou filantrópicos sob sua influência para combater os privilégios do catolicismo no País. Outro espaço privilegiado da atuação maçônica na sua luta contra a Igreja e os jesuítas foi no campo educacional. Assim, quando se tratava de educação, defendia o ensino laico em contraposição à obrigatoriedade do ensino religioso; quando tratava-se da ausência de registro civil, de nascimento e

\footnotetext{
${ }^{1}$ Professora do PPGH da Universidade de Passo Fundo (RS). Doutora em História do Brasil.
} 
casamento, acusava-se a Igreja Católica de manipular esse monopólio, desrespeitando as liberdades individuais de crença².

$\mathrm{O}$ anticlericalismo maçônico foi o fio condutor da maior parte das iniciativas e projetos maçônicos durante o século XIX no Brasil (as repercussões desse conflito estenderam-se até pelo menos os anos de 1920. Cabe ressaltar, que ser anticlerical não era uma exclusividade maçônica. A maior parte da elite política e intelectual bebia na mesma fonte que os maçons. $O$ pensamento liberal e cientificista encontrou um campo fértil e prosperou em diversos segmentos da sociedade brasileira. Assim, quando a maçonaria procurou atrair os setores sociais mais ilustrados em defesa da secularização da sociedade, encontrou muitos adeptos.

A secularização pretendida por esses grupos, levaria, em última instância, à separação entre Estado e Igreja. A subordinação do segundo ao primeiro sempre merecera ataques de ambos os lados. Mesmo assim, o clero católico beneficiavase da condição de ser religião oficial (confirmada na Constituição de 1824). O salário dos padre, as reformas nas igrejas, a administração nos cemitérios, são apenas alguns dos favorecimentos aos católicos.

O episódio conhecido como a questão religiosa foi um momento privilegiado do embate e da polêmica maçônicocatólica ${ }^{3}$. O clero brasileiro se opôs à crescente influência da maçonaria no campo das idéias e da cultura política, utilizandose da legislação papal para realizar uma verdadeira caça às

2 COLUSSI, Eliane Lucia. A maçonaria gaúcha no século XIX. Passo Fundo: Ediupf, 1998. p. 139-143.

${ }^{3}$ Durante o pontificado de Pio IX, entre 1846 a 1879 , houve um acirramento das relações entre maçonaria e Igreja Católica. A Igreja elegeu, naquele contexto, a maçonaria como a sua maior inimiga. Segundo Ferrer Benimeli, houve 28 documentos pontifícios de condenação à maçonaria e a outras sociedades secretas, unificados na constituição pontifícia Apostolicae Sedis, de 12 de dezembro de 1869. FERRER BENIMELI, Jose Antonio. La masonería actual. Sandanyola (Barcelona): Editora AHR, 1977. p. 47-48. 
bruxas entre seus próprios membros. Além disso, os bispos que de maneira mais violenta atacaram a instituição naquele contexto procuraram demarcar a sua posição antiliberal, portanto, contrária ao processo de secularização da sociedade brasileira.

Dois projetos diferentes no campo das idéias evidenciavase: o primeiro consubstanciado pela influência das correntes de pensamento liberal e cientificista no Brasil e que transpunha para a esfera da política e da cultura a defesa de noções, como racionalismo, progresso, modernidade; o segundo, uma reação do catolicismo mundial frente aos avanços do liberalismo, que, no Brasil, reuniu os defensores do pensament-católico-conservador.

Para a maçonaria, a educação e o ensino era um instrumento fundamental na difusão do ideário liberal e racionalista. Para ela, a igreja Católica exercia uma influência negativa, pois mantinha as crianças e os jovens no universo do obscurantismo e da superstição. Para fazer frente a essa situação, a maçonaria mobilizou-se. Objetivava, com isso, uma identificação do modelo educacional com o "espírito das luzes, libertadora da consciência dos homens e fiéis escudeiras no combate às trevas representadas pelo fanatismo da Igreja Católica"4.

A realidade educacional no Brasil do século XIX era gravíssima. $O$ descaso do governo e dos políticos no século XIX, principalmente durante o período imperial, deixou o ensino primário, secundário e profissional num abandono quase completo, quadro que iria ser alterado, lentamente, no período republicano. Até então, a rede escolar primária era precária, o corpo docente leigo e incompetente; a escola secundária freqüentada por parcelas minoritárias e ricas da população, onde ministravam-se um ensino literário; o ensino superior era ainda mais frágil e desvinculado da realidade nacional ${ }^{5}$.

\footnotetext{
${ }^{4}$ BARATA, Alexandre Mansur. Luzes e sombras: a ação dos pedreiros-livres brasileiros (1870-1910). Niterói. UFF, 1992. (Dissertação de Mestrado). p.165. ${ }^{5}$ WEREBE, Maria José Garcia. A educação. In: HOLANDA, Sérgio Buarque de. (Org.). História geral da civilização brasileira. São Paulo: Difel, 1985. v. 6, p. 382.
} 
A imprensa maçônica publicou freqüentemente, suas preocupações e seus posicionamentos em relação ao tema. Em primeiro lugar, defendia firmemente a obrigatoriedade do ensino aos jovens pois, "não basta esperar que o homem mande seu filho para a escola, que é a universidade do ensino primário; convém impor-lhe essa obrigação e aliás com aquele lógico rigor de que serve a lei"

Saldanha Marinho, líder maçônico de maior expressão nas décadas de 1870 e 1880, dedicou uma parte dos seus ataques ao catolicismo ultramontano. Na sua avaliação, a Igreja Católica pretendia se assenhorear do ensino público e, consequentemente, dominar o povo. Para o líder maçom, o governo imperial só admitia proteção aos seus ultramontanos e:

E para isso quer afugentar das escolas públicas os hereges, os condenados, os réprobos, segundo a qualificação da cúria romana; porque s. ex., prefere estar de acordo com a Santa Sé, a curar com zelo dos legítimos interesses do pais!?

A maçonaria, na sua luta contra a Igreja ultramontana, elegeu os integrantes da Companhia de Jesus como seus maiores inimigos. Esse enfrentamento durou desde a década de 1870 até pelo menos os anos de 1920. O retorno dos jesuítas ao Brasil e a inserção crescente destes no campo educacional em várias partes do Brasil constituía-se numa ameaça aos livrepensadores. Os maçons criticavam a doutrinação existente em seus colégios e a completa ausência das doutrinas do espírito moderno.

O texto que segue é revelador do posicionamento maçom em relação a influência jesuítica no ensino:

\footnotetext{
${ }^{6}$ Boletim do Grande Oriente do Brasil. Ano 2, n. 12, dezembro de 1873. p. 892.

7 MARINHO, Saldanha. A Igreja e o Estado. In: A Acácia - folha maçônica. 1876, ano 1, n. 50. p. 1.
} 
Os jesuítas, é sabido, usam dos seus colégios para fazer proselitos. Dominar a instrução da mocidade é o seu constante empenho e, como eles sabem captar a confiança dos pais, di-lo o sucesso que sempre alcançam, vencendo os escrúpulos até de seus adversários que lhes confiam os filhos ${ }^{8}$.

Foi também a partir de 1870 que surgiram as primeiras propostas de lojas maçônicas visando a iniciação de professores na maçonaria. A maior parte desses profissionais não podiam fazer parte da ordem já que, na sua maioria, não dispunham dos recursos financeiros suficientes para pagar as despesas exigidas de filiação; apenas aqueles profissionais liberais ou homens de alguma fortuna que também exerciam a função de professores eram o alvo principal da maçonaria, pois, por questão de origem social, eram sempre bem-vindos os cultos e letrados.

O ingresso de professores na maçonaria, especialmente os que atuavam na instrução pública, passou a ser visto como um dos meios mais eficientes para que a ordem buscasse ter acesso e influenciar na formação laica dos setores populares. A primeira iniciativa importante nesse sentido foi localizada em Porto Alegre, onde a loja Zur Eintracht aprovou uma resolução, na sessão de 14 de junho de 1876, que previa: "Aqueles professores que pela sua vida e costumes são dignos de pertencerem a ordem dos Franco-maçons e são propostos nesta Loja com as formalidades do rito, podem ser aceitos e iniciados, independente do pagamento de jóia e mensalidades"9.

Os professores, merecedores de convite para ingresso na maçonaria, deveriam ser propostos na forma de costume por um irmão maçom. Este serviria de fiador e a Loja, além das

\footnotetext{
${ }^{8}$ Boletim do Grande Oriente do Rio Grande do Sul. Ano 8, n. 6, outubro de 1899. p. 56-57.

9 Uma resolução importante. A Acácia-folha maçônica. 1876, ano 1, n. 24. p. 3.
} 
sindicâncias de costume, nomearia uma comissão especial para relatar, em sessão, sobre a vida e os costumes e as habilitações profissionais do indivíduo. Esta disposição não se estenderia aos professores que, notoriamente, tivessem meios necessários para realizarem as contribuições pecuniárias, sem grande ônus para si ou para sua família ${ }^{10}$.

As qualidades individuais exigidas para a iniciação de um profano na maçonaria seriam as mesmas daquelas impostas aos professores que não tinham os recursos materiais indispensáveis à vida maçônica. O seu caráter elitista, então, esteve condicionado às próprias necessidades de penetração social da maçonaria em determinadas circunstâncias. Mesmo que não tenhamos localizado muitas iniciativas como essa, a constatação de que houve um crescente número de professores sendo iniciados em oficinas ${ }^{11}$ confirma essa diretriz maçônica. pois "é inegável a conveniência que há em chamar-se ao grêmio da nossa Subl $\backslash$ Ord $\backslash$ o maior número possível de instrutores da mocidade"12.

Além da defesa do ensino obrigatório, outra estratégia maçônica importante apareceu a partir do decênio de 1870 . Frente a ineficiência do ensino público e da influência católica no ensino privado, iniciou-se uma campanha, no interior da maçonaria, para a criação de colégios maçônicos. As primeiras notícias veiculadas na imprensa maçônica, sugeriam que já era tempo de existirem colégios maçônicos, sendo "inexplicável que ainda não existam"13.

\footnotetext{
10 Idem.

11 Oficina é um termo genérico que serve para designar todo e qualquer agrupamento maçônico: loja, capítulo, conselho filosófico. Na linguagem corrente, a palavra tornou-se sinônimo do termo loja. MELLOR, Alec. Dicionário da francomaçonaria e dos franco-maçons. São Paulo: Martins Fontes, 1989. p. 196.

${ }_{12}$ A Acácia-folha maçônica. 1876, ano 1, n. 24. p. 3.

${ }^{13}$ Colégio Maçônico. In: Boletim do Grande Oriente do Brasil. 1876, ano 5, n. 10. p. 382 .
} 
O estudo de Alexandre Barata, confirma as inúmeras iniciativas maçônicas de criação de escolas. O autor informa que ainda em 1872 foi fundada, no Rio de Janeiro, uma escola maçônica com o nome de Vesper, cuja finalidade era difundir a instrução nas classes populares ${ }^{14}$. Entretanto, essas iniciativas mantiveram-se inexpressivas até praticamente o final do século XIX. As dificuldades de manutenção financeira contribuíram para as frustradas tentativas.

As dificuldades de implementação de projetos educacionais / escolares próprios não impediu a ordem maçônica de buscar alternativas frente a inoperância do Estado e a influência católica. $\mathrm{Na}$ ausência de escolas próprias, a maçonaria, por meio dos seus órgãos de imprensa, orientava os seus filiados para que matriculassem os filhos em escolas particulares, cujos proprietários, via de regra, eram homens identificados com o anticlericalismo e com as idéias liberais. A garantia de uma linha de ensino cientificista e laica era condição de aprovação maçônica.

O contexto em que as iniciativas de criação de escolas maçônicas expandiram-se foi justamente a partir da proclamação e consolidação do Brasil republicano. Durante praticamente 30 anos, na maioria das cidades em que existiam lojas instaladas, funcionavam também escolas. A existência de escolas não significava a garantia de seu bom funcionamento e clientela expressiva. Ao contrário, a maioria das iniciativas foram frustradas e, a estratégia de luta anticlerical no campo educacional pode ser considerada uma derrota para a maçonaria.

Mesmo assim, ainda em 1922, o Grande Oriente do Brasil, através do decreto n. 513, reafirmava a necessidade de manutenção dos projetos escolares maçons. No artigo $2^{\circ}$, aparece: "Em todos os Orientes onde não houver escolas gratuitas mantidas pelo governo do pais, ou por associação leiga

${ }^{14}$ BARATA, Alexandre Mansur. Luzes e Sombras... Op. cit. p. 166.

Hist. Ensino, Londrina, v. 6, p. 47-56, out. 2000 
de qualquer natureza, as Lojas e os maçons aí residentes, são obrigados a suprir essa falta, e a essa missão de preferência dedicar todos os sacrifícios de que forem suscetíveis, coletiva e pessoalmente". No mesmo ano desse decreto, existiam no Brasil 128 escolas em funcionamento ${ }^{15}$.

Importante salientar que as escolas maçônicas, a partir do final do século XIX, caracterizaram-se por priorizar o ensino noturno e dirigido às classes trabalhadoras ou populares. Naquele contexto, a perspectiva filantrópica da maçonaria dirigiu tais iniciativas no sentido da ampliação de sua influência nesses segmentos da sociedade. Outra característica foi a curta duração da maioria dessas iniciativas, já que as escolas, de forma geral, funcionaram em média apenas dois ou três anos. cumprindo, então, as orientações e diretrizes do período, ficava sempre explícito o objetivo a ser atingido com a criação de determinada escola:

As transformações significativas, principalmente com a separação Estado/Igreja, confirmaram a vitória dos liberais e defensores da secularização da sociedade. No que concerne à educação e ao ensino, ocorreu a confirmação da sua secularização, cuja vitória parecia vir por meio da eliminação do ensino religioso nos currículos escolares. Frente à situação, a Igreja Católica se posicionou contrariamente à medida; contudo, apesar das pressões, não conseguiu revertê-la antes de 1931.

A atuação da maçonaria, por meio das ações filantrópicas e beneficentes, da preocupação com o acesso ao ensino por parte dos jovens e pobres, deixou uma contribuição positiva na história brasileira. Os maçons foram formadores de uma cultura política de elite, ocupando espaços importantes para o caminho da secularização da sociedade brasileira, confirmada, em parte, pelo advento da República em 1889.

\footnotetext{
15. ALBUQUERQUE, Arci Tenório de. O que é maçonaria. Rio de Janeiro: Aurora, s/d. p. $180-181$.
} 
A secularização tinha como objetivo, para a maioria dos maçons, pôr fim ao obscurantismo e às superstições, os quais, estavam incorporados na presença do catolicismo como religião oficial do Estado brasileiro e, sobretudo, na crescente influência jesuítica no ensino.

\section{Bibliografia}

ALBUQUERQUE, Arci Tenório de. O que é maçonaria. Rio de Janeiro: Aurora, s/d.

BARATA, Alexandre Mansur. Luzes e sombras: a ação dos pedreiros-livres brasileiros (1870-1910). Niterói. UFF, 1992. (Dissertação de Mestrado).

COLUSSI, Eliane Lucia. A maçonaria gaúcha no século XIX. Passo Fundo: Ediupf, 1998.

FERRER BENIMELI, Jose Antonio. La masonería actual. José Antônio. La masonería actual. Sandanyola (Barcelona): Editora AHR, 1977.

MARINHO, Saldanha. A Igreja e o Estado. In: A Acácia - folha maçônica. 1876, ano 1, n. 50. p. 1.

MELLOR, Alec. Dicionário da franco-maçonaria e dos francomaçons. São Paulo: Martins Fontes, 1989.

WEREBE, Maria José Garcia. A educação. In: HOLANDA, Sérgio Buarque de. (Org.). História geral da civilização brasileira. São Paulo: Difel, 1985. v. 6, p. 382.

\section{Fontes Primárias}

A Acácia -folha maçônica. Porto Alegre (1876-1877).

Boletim do Grande Oriente do Brasil. Rio de Janeiro (1871-1900). Boletim do Grande Oriente do Rio Grande do Sul. Porto Alegre (1899). 
Abstract: The present article aims at to analyze the influence of the freemasonry in the defense of the lay teaching during the Brazilian imperial period. The freemasonry, present in the Brazilian history from the previous period the proclamation of the independence, assumed during the XIX century, openly anticlerical positioning. The field of the education was considered, for the freemason, fundamental in their anticlerical fight.

Keywords: political history, freemasonry, education, Catholic Church. 